\title{
Two-stage two-dimensional spatial competition between two firms
}

\section{$\operatorname{AUTHOR}(\mathrm{S})$ :}

Tabuchi, Takatoshi

\section{CITATION:}

Tabuchi, Takatoshi. Two-stage two-dimensional spatial competition between two firms. 京都大学経済学部Working Paper 1991, 16

\section{ISSUE DATE:}

1991

URL:

http://hdl.handle.net/2433/37911

RIGHT: 
TWO-STAGE TWO-DIMENSIONAL SPATIAL COMPETITION

BETWEEN TWO FIRMS*

by

Takatoshi Tabuchi

Faculty of Economics

Kyoto University

Faculty of Economics,

Kyoto University,

Kyoto, 606 JAPAN 
WORKING PAFER NO. 16

TWO-STAGE TWO-DIMENSIONAL SPATIAL COMPETITION BETWEEN TWO FIRMS*

by

Takatoshi Tabuchi

Faculty of Economics

Kyoto University 


\section{INTRODUCTION}

Although urban location of firms is better analyzed by two-dimensional space, it is usually examined by one-dimensional space in the literature on spatial competition à la Hotelling (1929) due to mathematical tractability. However, observing urban areas in the real world, we hardly find long narrow (one-dimensional) cities. Similarly in differentiated product space, we seldom find commodities which can be depicted only by single characteristic. The one-dimensional approximation may not be accepted unless we obtain equivalent results. To investigate the validity is one of the purposes of this paper.

In studying spatial competition of oligopolistic firms, we must be faced with a troublesome obstacle of the nonexistence of Nash price equilibrium. That is to say, as shown by d'Aspremont, Gabszewitz and Thisse (1979), there exists no price equilibrium in one-dimensional space under a linear transportation cost when duopolists locate close. Later, Champsaur and Rochet (1988) revealed that so as to guarantee the existence of a price equilibrium in pure strategies, we have to limit a family of transportation cost function substantially. 1 Without existence of price equilibrium for all locational pairs, payoff functions of the firms are not defined globally, which prevents us from knowing the overall locational behavior of the firms.

A similar argument applies for the Nash location game under a fixed price. It is well known that there exists no location equilibrium in pure strategies when the market is a line segment or a disc, and the number of firms is three (Shaked, 1975) although they tend to locate around the center.

These findings imply that unless firms are allowed to take mixed strategies, both price equilibrium and location equilibrium exist under a very limited set of the number of firms, transportation cost functions, and consumer distribution functions. Needless to say, in analyzing multistage games, existence of these equilibria is necessary. In this paper, therefore, we will presuppose duopolistic firms, a quadratic transportation cost, and uniform rectangular distributions of consumers. The first two are frequently appeared in 
the literature as they together ensure the existence of price equilibrium in one-dimensional space. The last one is uncommon and is an extension of one-dimensional to two-dimensional distribution of consumers. A conversion method we developed here will enable us to explore the two-dimensional world maintaining the existence of price equilibrium. The method is applied to any convex set of uniform consumer distributions given a quadratic transportation cost and two firms.

We deal with subgame perfect Nash equilibrium. That is, we consider a situation that two firms compete in location in the first stage anticipating the subsequent price competition in the second stage. The locations cannot be altered in the second stage. In the context of spatial competition, such a change in location is seldom done due to irreversible nature of urban building capital. In characteristics competition, such a change in model type is usually very costly because of existence of scale economies in production.

We also analyze sequential entry of firms with simultaneous price competition. Specifically, one firm enters the spatial market in the first stage, the other firm enters the market in the second stage, and then they compete in price in the final stage. In other words, the former two stages are a Stackelberg location game while the latter stage is a Nash price game. A comparison is made between this sequential location model with the simultaneous location model.

Our emphasis is placed upon the difference between one-dimensional and two-dimensional problems. According to d'Aspremont et al. (1979), the principle of maximal differentiation holds in one-dimensional space. However, we shall demonstrate that this is not true in two-dimensional space. If the space is rectangular, then firms do not locate at opposite corners, but at midpoints of opposite sides, implying that differentiation is maximal in one dimension whereas it is minimal in the other dimension. Neven and Thisse (1990) obtained a similar result by assuming horizontal differentiation on one dimension and vertical differentiation in the other dimension. Here, we assume two dimensions of horizontal differentiation, where no a priori difference exists between the 
two.

The paper is organized as follows. The two-stage location-price game is briefly depicted in Section 2, and a conversion method between one-dimensional non-uniform distributions of consumers and two-dimensional uniform distributions of consumers is stated in Section 3.

After solving the second-stage Nash price game, we concentrate on the first-stage Nash location game for rectangular distributions of consumers in Section 4. In Section 5, we modify the Nash location game to a Stackelberg location game in the first stage while the second stage of the Nash price game remains the same. Section 6 makes a welfare comparison between the Nash location equilibrium in Section 4 and the Stackelberg location equilibrium in Section 5. Section 7 then concludes the paper.

\section{THE MODEL SETTING}

Consumers who purchase a unit of good are uniformly distributed over a convex set $\mathbb{C}$ on $\mathbb{R}^{2}$, where $\int_{\mathbb{C}} \mathrm{dxdy}=1$. Anticipating consequences of the second-stage competition, firm 1 locates at $\left(\mathrm{x}_{1}, \mathrm{y}_{1}\right) \in \mathbb{C}$ and firm 2 locates at $\left(\mathrm{x}_{2}, \mathrm{y}_{2}\right) \in \mathbb{C}$, in the first stage. They are not allowed to locate outside $\mathbb{C}$ due to, say a zoning regulation or a geographic constraint. In the second stage, they choose their own mill price $\mathrm{p}_{1}$ and $\mathrm{p}_{2}$ respectively holding the locations fixed. The transportation cost which a consumer has to incur is assumed to be a quadratic function of distance between the consumer and the nearer firm.

Suppose the unit transportation cost is unity without loss of generality, a marginal consumer at $(\mathrm{x}, \mathrm{y})$ is indifferent between firms 1 and 2 , where

$$
\mathrm{p}_{1}+\left(\mathrm{x}_{1}-\mathrm{x}\right)^{2}+\left(\mathrm{y}_{1}-\mathrm{y}\right)^{2}=\mathrm{p}_{2}+\left(\mathrm{x}_{2}-\mathrm{x}\right)^{2}+\left(\mathrm{y}_{2}-\mathrm{y}\right)^{2},
$$

which is always a straight line.

Assuming zero production cost again without loss of generality, each firm maximizes its profit:

$$
\Pi_{1}=\mathrm{p}_{1} \mathrm{D}_{1}, \quad \Pi_{2}=\mathrm{p}_{2}\left(1-\mathrm{D}_{1}\right)
$$


with respect to location and then price, where $D_{1}=\int_{\mathbb{C}_{1}} d x d y$, and $\mathbb{C}_{1}=\left\{(\mathrm{x}, \mathrm{y}) \in \mathbb{C} \mid \mathrm{p}_{1}+\left(\mathrm{x}_{1}-\mathrm{x}\right)^{2}+\left(\mathrm{y}_{1}-\mathrm{y}\right)^{2} \leq \mathrm{p}_{2}+\left(\mathrm{x}_{2}-\mathrm{x}\right)^{2}+\left(\mathrm{y}_{2}-\mathrm{y}\right)^{2}\right\}$. Note that the measure of the boundary is nil, and so ignored.

The analysis is confined to the case of pure strategies. In order to get the subgame perfect equilibrium, we first solve the second-stage problem of profit maximization with respect to price given the locations. As we assume that the transportation cost is a quadratic function of distance and $\mathbb{C}$ is a convex set, we can employ the following proposition.

Proposition 1 (Caplin and Nalebuff, 1991)

For any given locations of firms and for any log-concave density function of consumers in $\mathbb{R}^{\mathrm{n}}$, a unique Nash price equilibrium exists.

From this, it follows that any convex set of $\mathbb{C}$ in $\mathbb{R}^{2}$ guarantees the existence of a unique price equilibrium. It should be noted that Proposition 1 is not applicable when the transportation cost is linear. Although the demand becomes continuous in two dimensions under the linear transportation cost, the profit function is not necessarily quasi-concave, which may not guarantee the existence of a unique price equilibrium (Economides, 1986). We will focus only on this set in the reminder of the paper.

\section{CONVERSION FROM TWO-DIMENSIONNAL TO ONE-DIMENSIONAL SPACE}

The quadratic transportation cost not only ensures the existence of price equilibrium, but also generates a straight line division of the market. This enables us to convert a two-dimensional uniform distribution of consumers into a one-dimensional non-uniform distribution of consumers, which greatly eases analysis. Notice that so as to obtain the best locational reply in the first stage, we must consider any pair of firm 
locations, for which the log-concavity should be satisfied after projecting the two-dimensional distribution onto one-dimensional one. We show below that the uniform distribution over a convex set on $\mathbb{R}^{2}$ is a sufficient condition for the concave distribution in $\mathbb{R}$. In other words, if we project the uniform distribution of consumers over a convex set on $\mathbb{R}^{2}$ at any angle (i.e., for any pair of firm locations), the distribution always becomes concave in $\mathbb{R}$ guaranteeing a unique price equilibrium.

Specifically, under the assumptions in the previous section, let us set the new axis, called $\mathrm{X}$ axis, parallel to the line passing through the two firms' locations, $\left(\mathrm{x}_{1}, \mathrm{y}_{1}\right)$ and $\left(\mathrm{x}_{2}, \mathrm{y}_{2}\right)$ as drawn in Figure 1. Then, the market split line segment BD, which is equation (1), becomes perpendicular to the $\mathrm{X}$ axis. Due to the nature of the quadratic distance cost, all consumers at the same $\mathrm{X}$ are considered identical to the firms. That is, we can project the two-dimensional convex set of the uniform distribution of consumers onto the $\mathrm{X}$ axis, so that it becomes a one-dimensional non-uniform concave distribution of consumers.

[Figure 1 about here]

Mathematically, define a convex set of two-dimensional uniform distribution of consumers as $\mathbb{C}=\left\{(X, Y) \in \mathbb{R}^{2} \mid \mathrm{g}(\mathrm{X}, \mathrm{Y}) \leq 0\right\}$ in the $\mathrm{X}-\mathrm{Y}$ coordinates. The demand is measured by the one-dimensional function as $D_{1}=\int_{\mathbb{C}_{1}} h_{1}(X)-h_{2}(X) d X$, where $Y=h_{1}(X)$ and $\mathrm{Y}=\mathrm{h}_{2}(\mathrm{X})\left[\mathrm{h}_{1}(\mathrm{X}) \geq \mathrm{h}_{2}(\mathrm{X})\right]$ are two implicit functions derived from the boundary $\mathrm{g}(\mathrm{X}, \mathrm{Y})=0$. In Figure $1, Y=h_{1}(X)$ is the $\operatorname{arc} A B C, Y=h_{2}(X)$ is the arc $A D C$, and $D_{1}$ is the shaded area. Since $\mathbb{C}$ is convex, $h_{1}(X)$ is concave and $h_{2}(X)$ is convex, and hence $h_{1}(X)-h_{2}(X)$ is concave. We can therefore work with the model of one-dimensional concave distribution of consumers, where Proposition 1 applies.

Now, let $\mathrm{f}(\mathrm{X})$ denote the concave density function of consumers in one-dimensional space and $F(X)$ be the cumulative distribution function of consumers, where 
$F(X) \equiv \int_{\underline{X}}^{X} f(Z) d Z$ and $F(X)=1$. Notice that $D_{1}=F\left(X_{1}\right)$.

By use of (1) and (2), the first-order conditions for profit maximization with respect to its own price are given by

$$
\frac{\partial \Pi_{1}}{\partial \mathrm{p}_{1}}=\mathrm{F}(\hat{\mathrm{X}})-\frac{\mathrm{p}_{1} \mathrm{f}(\hat{\mathrm{X}})}{2\left(\mathrm{X}_{2}-\mathrm{X}_{1}\right)}=0, \quad \frac{\partial \Pi_{2}}{\partial \mathrm{p}_{2}}=1-\mathrm{F}(\hat{\mathrm{X}})-\frac{\mathrm{p}_{2} \mathrm{f}(\hat{\mathrm{X}})}{2\left(\mathrm{X}_{2}-\mathrm{X}_{1}\right)}=0 .
$$

Solving these two equations with (1), we have

$$
\mathrm{G}(\hat{\mathrm{X}}) \equiv 2 \mathrm{~F}(\hat{\mathrm{X}})-1+\left[\hat{\mathrm{X}}-\frac{\mathrm{X}_{1}+\mathrm{X}_{2}}{2}\right] \mathrm{f}(\hat{\mathrm{X}})=0 .
$$

From Proposition 1, equation (4) determines a unique market boundary $\hat{\mathrm{X}}$ in Nash price equilibrium for any concave distribution of consumers, given locations of $X_{1}$ and $X_{2}$.

\section{NASH LOCATION GAME}

We will prove in this section that two firms never locate at the interior region in any rectangular distribution, where consumers are uniformly distributed. We shall fully identify Nash location equilibria for any rectangular distribution of consumers, and analyze Stackelberg location equilibrium in the next section. A welfare comparison of these equilibria are made in Section 6.

We know from Proposition 1 that since rectangles are convex, for any location pair there always exists a unique price equilibrium in the second-stage competition. We shall therefore focus our analysis only upon the first-stage location equilibrium hereafter. Firm $i$

maximizes $\Pi_{i}^{*}\left(x_{i}, y_{i}, x_{j}, y_{j}\right)$ with respect to $x_{i}, y_{i}$ for $i \neq j$, knowing the subsequent price competition with perfect foresight. It should be noted that although each profit function is quasi-concave with respect to its price for any concave density (Proposition 1), it is not necessarily quasi-concave with respect to its location. This forces us to examine only a limited family of consumer distributions since we cannot investigate the subgame perfect equilibrium without existence of price equilibrium and location equilibrium. 
In the beginning, consider a uniform distribution of consumers over a rectangle whose lengths of sides are $c$ by $1 / c: \mathbb{C}_{1}=\left\{(x, y) \in \mathbb{R}^{2} \mid 0 \leq x \leq c, 0 \leq y \leq 1 / c\right\}$. Without loss of generality, assume $0 \leq \mathrm{x}_{1} \leq \mathrm{x}_{2} \leq \mathrm{c}$ and $0 \leq \mathrm{y}_{1} \leq \mathrm{y}_{2} \leq 1 / \mathrm{c}$. Define $\mathrm{x}_{\mathrm{a}}$ such that $\left(\mathrm{x}_{\mathrm{a}}, 0\right)$ is on the market split line of equation (1); $x_{b}$ such that $\left(x_{b}, 1 / c\right)$ is on $(1) ; y_{a}$ such that $\left(0, y_{a}\right)$ is on (1); and $\mathrm{y}_{\mathrm{b}}$ such that $\left(c, \mathrm{y}_{\mathrm{b}}\right)$ is on (1). Notice that the line of (1) is at right angles to the line passing through $\left(\mathrm{x}_{1}, \mathrm{y}_{1}\right)$ and $\left(\mathrm{x}_{2}, \mathrm{y}_{2}\right)$, whose slope is $\left(\mathrm{y}_{2}-\mathrm{y}_{1}\right) /\left(\mathrm{x}_{2}-\mathrm{x}_{1}\right) \equiv \alpha$. In Figure 2, this is shown by the dotted line while the market boundary is the solid line. Depending upon the values of $\mathrm{x}_{\mathrm{a}}, \mathrm{x}_{\mathrm{b}}, \mathrm{y}_{\mathrm{a}}$ and $\mathrm{y}_{\mathrm{b}}$, divisions of the rectangular market are classified into four cases as in Figure 2(i), 2(ii), 2(iii) and 2(iv).

[Figure 2 about here]

So as to obtain the Nash equilibrium, we start from the set of Lemmas. All proofs are relegated to the Appendix.

\section{Lemma 1}

Given firm $j$ 's location of $\left(\mathrm{x}_{\mathbf{j}}, \mathrm{y}_{\mathbf{j}}\right) \in \mathbb{C}_{1}$, firm $i(\neq j)$ locates either at a corner or at a midpoint of one side.

Lemma 1 implies that at least one of the duopolist does not choose the interior region of $\mathbb{C}_{1}$. Since there are four corners and four sides on a rectangle, there exist eight possible locations for one duopolist in this game. Due to symmetry of rectangles, however, it suffices to analyze only two possible locations of firm 1: $(0,0)$ and $(0,1 / 2 \mathrm{c})$, where $c \in(0, \infty)$. The best locational reply of firm 2 against firm 1's location $(0,0)$ is analyzed in Lemma 2, and that against firm 1's location $(0,1 / 2 \mathrm{c})$ is examined in Lemma 3 below.

\section{Lemma 2}


If one firm locates at a corner, then the other firm locates at a midpoint of one side which is farthest from the corner.

\section{Lemma 3}

If one firm locates at a midpoint of one side, then the other firm locates at one of three other midpoint. More precisely, given the firm 1's location of $(0,1 / 2 \mathrm{c})$, firm 2 locates at $(\mathrm{c} / 2,0)$ or $(\mathrm{c} / 2,1 / \mathrm{c})$ if $\mathrm{c} \leq \mathrm{c}_{\mathrm{o}}$, and locates at $(\mathrm{c}, 1 / 2 \mathrm{c})$ if $\mathrm{c} \geq \mathrm{c}_{\mathrm{O}}$, where $\mathrm{c}_{\mathrm{o}}=\sqrt{3 \sqrt{2}-\sqrt{13}} \simeq 0.798$.

We thus showed in Lemmas 2 and 3 that the best locational reply to a corner or a midpoint is a midpoint. These results will lead to Proposition 2 demonstrating the location of midpoints of opposite sides. Before moving to Proposition 2, let us examine economic implications of Lemma 3.

Suppose $c$ lies within the interval of $\left((1 / 3)^{1 / 4}, c_{0}\right) \simeq(0.76,0.80)$. Given the firm 1's location of $(0,1 / 2 \mathrm{c})$, firm 2 chooses to locate at $(\mathrm{c} / 2,0)$ or $(\mathrm{c} / 2,1 / \mathrm{c})$ rather than the opposite midpoint $(c, 1 / 2 c)$ from Lemma 3 . The distance between the two firms in the former two cases $\left(\sqrt{1+c^{4}} / 2 c\right)$ is smaller than that in the latter case $(c / 2)$, and the firm 2 's share in the former two cases $\left(\left(5+c^{4}\right) / 12\right)$ is smaller than that in the latter case $(1 / 2)$. Apparently, such a closer location may intensify price competition and reduces the share, it seems irrational locational behavior under one-dimensional uniform distributions of consumers.

However, such behavior does take place in two-dimensional (or one-dimensional non-uniform) distributions as a rational locational reply. The reason is intuitively understood if we compare the number of marginal consumers in the above example. The number of marginal consumers in the former two cases turns out to be less than that in the latter case because the ratio of the former to the latter $c \sqrt{1+c^{4}}$ is less than unity for all $c \in\left((1 / 3)^{1 / 4}, c_{0}\right)$. When the number of marginal consumers becomes smaller, firms would 
not lower prices to acquire additional marginal consumers. They would rather raise prices to increase the revenue from non-marginal consumers. Examining such possibility, we obtain the following.

Remark 1

Relaxing price competition is possible by locating closer if the number of marginal consumers becomes smaller.

Now, we are ready to prove Proposition 2 which fully characterizes the Nash location equilibrium in two-dimensional space.

\section{Proposition 2}

If $\mathbb{C}$ is a rectangle close to a square, then firms locate at the opposite midpoints of short or long sides. Otherwise, firms locate at the opposite midpoints of the short sides.

More precisely, the two-stage Nash equilibrium locations are given by

$$
\begin{aligned}
\left(\mathrm{x}_{1}^{*}, \mathrm{y}_{1}^{*}, \mathrm{x}_{2}^{*}, \mathrm{y}_{2}^{*}\right) & =(\mathrm{c} / 2,0, \mathrm{c} / 2,1 / \mathrm{c}) & & \text { for } \mathrm{c}<\mathrm{c}_{\mathrm{o}^{\prime}} \\
& =(\mathrm{c} / 2,0, \mathrm{c} / 2,1 / \mathrm{c}) \text { or }(0,1 / 2 \mathrm{c}, \mathrm{c}, 1 / 2 \mathrm{c}) & & \text { for } \mathrm{c}_{\mathrm{o}} \leq \mathrm{c} \leq 1,
\end{aligned}
$$

where $\mathrm{c}_{\mathrm{o}} \simeq 0.798$.

In brief, Proposition 2 implies in a context of product characteristics space that firms tend to maximize product differentiation in one characteristic (location of each side) while they minimize it in the other characteristic (location at a center of each side). Note that product differentiation is not maximal. Moreover, when the rectangle is close or equal to a square, there exist two location equilibria; and when the rectangle is long and slender, there exists a unique location equilibrium. ${ }^{2}$ Firms succeed in relaxing price competition by locating apart each other in the latter case, but not necessarily in the former case. Nonetheless, we will show in the next section that if firms enter the market sequentially 
rather than simultaneously, they always succeed to locate apart.

Proposition 2 also implies that neither firm locates at the interior region in Nash equilibrium. Needless to say, the non-interior equilibrium location is a necessary consequence of dominance of the price competition over the location one. ${ }^{3}$ Rational firms move apart each other to avoid cutthroat competition.

\section{STACKELBERG LOCATION GAME}

While the model in Section 4 is simultaneous choice of location, here it is modified to sequential choice of location, i.e., the first stage is a Stackelberg leader-follower location game while the second stage is a Nash price subgame.

Mathematically, firm 1 (the leader) maximizes its profit of $\Pi_{1}^{*}\left(\mathrm{x}_{1}, \mathrm{y}_{1}, \mathrm{x}_{2}, \mathrm{y}_{2}\right)$ with respect to $\mathrm{x}_{1}$ and $\mathrm{y}_{1}$, replacing $\mathrm{x}_{2}$ and $\mathrm{y}_{2}$ with firm 2's (the follower's) reply functions $\mathrm{x}_{2}=\mathrm{R}_{\mathrm{x}}\left(\mathrm{x}_{1}, \mathrm{y}_{1}\right)$ and $\mathrm{y}_{2}=\mathrm{R}_{\mathrm{y}}\left(\mathrm{x}_{1}, \mathrm{y}_{1}\right)$, which are derived from the maximization of $\Pi_{2}^{*}\left(\mathrm{x}_{1}, \mathrm{y}_{1}, \mathrm{x}_{2}, \mathrm{y}_{2}\right)$ with respect to $\mathrm{x}_{2}$ and $\mathrm{y}_{2}$.

In seeking the Stackelberg-location and Nash-price equilibrium, we take the following logical steps. In general, there are three kinds of firm locations: the midpoint, corner or inside. However, we know from Lemma 1 that firm 2, the follower, locates either at the midpoint or the corner. In Lemma 5 below, we prove that firm 2 always locates only at the midpoint. Based upon this, we examine the behavior of firm 1, the leader, and show that it necessarily locates at the midpoint of the short side. Let us begin with Lemma 4 as preliminary arrangements for subsequent analysis.

\section{Lemma 4}

For $\mathrm{x}_{1} \leq \mathrm{x}_{2}$ and $\mathrm{y}_{1} \leq \mathrm{y}_{2}$, the following inequalities hold:

$$
\frac{\partial \Pi_{1}^{*}{ }^{\mathrm{ii}}}{\partial \mathrm{x}_{2}}>0, \quad \frac{\partial \Pi_{1}^{*} \mathrm{ii}}{\partial \mathrm{y}_{2}} \gtreqless 0 \text { for } \mathrm{y}_{2} \gtreqless \frac{1}{2 \mathrm{c}},
$$




$$
\frac{\partial \Pi_{1}^{* \mathrm{iv}}}{\partial \mathrm{x}_{2}}>0, \quad \frac{\partial \Pi_{1}^{* \mathrm{iv}}}{\partial \mathrm{y}_{2}}>0
$$

where the Roman numerals at the superscripts correspond to those in the proof of Lemma 1.

Lemma 4 means that for firm 2, the follower, the midpoint is the best locational reply in case (ii), and the corner is the best locational reply in case (iv). On the other hand, firm 1, the leader, may locate at the midpoint, the corner or inside. For example, it might be possible for firm 1 to locate inside $\mathbb{C}_{1}$ anticipating that firm 2 would locate at the most distant corner [case (i) in Figure 2]. In Lemma 5, however, we are able to exclude such possibility since the corner location is shown to be a suboptimal locational reply for firm 2.

\section{Lemma 5}

The second entrant chooses to locate at the midpoint of one side.

The outline of the proof is as follows. From Lemma 1, the midpoint and the corner are the only two candidates for firm 2's location. Knowing this, firm 1 necessarily locates at the midpoint in the former case, where case (ii) applies. In the latter case, firm 1 may locate inside, where case (iv) applies with permutation of firm indices. Computing the maximum profit of firm 1 in each case, the former profit is shown to be larger, which leads to the midpoint location of firm 2 .

By use of Lemma 5, we are now ready to establish Proposition 5 below:

\section{Proposition 3}

Each firm locates at a point of the short side in two-stage Stackelberg location and Nash price equilibrium. 
Thus, with the exception that $\mathbb{C}_{1}$ is a square, we observe that the Stackelberg location equilibrium is always unique whereas the Nash location equilibrium is not when $c \in\left[c_{0}, 1 / c_{0}\right]$. In other words, the sequential location eliminates one of the multiple equilibria, where the firm's profit is lower. This is because firm 1 is able to relax the price competition by choosing the midpoint of the short side. Such behavior cannot be possible in the Nash simultaneous location game since there is no leader-follower distribution between the firms.

The profit of each firm in Stackelberg location equilibrium is then greater than or equal to that in Nash location equilibrium. Consequently, we conclude that firms may be worse off if they choose to locate simultaneously rather than sequentially. It should be noticed that such difference does not arise in one-dimensional uniform distribution of consumers.

\section{WELFARE COMPARISON}

Let us finally conduct a welfare comparison of the above subgame perfect equilibrium locations and the social optimal locations. In the absence of the production costs and the price elasticity, we can evaluate the social welfare solely by the sum of the total transportation costs incurred by consumers who are uniformly distributed on a rectangle of $\mathrm{c}$ by $1 / \mathrm{c}$.

The welfare loss, defined by the sum of quadratic distance costs between consumers and their nearest firms, ${ }^{4}$ is expressed as

$$
\mathcal{L} \equiv \sum_{i=1}^{2} \iint_{\mathbb{C}_{i}}\left(x_{i}-x\right)^{2}+\left(y_{i}-y\right)^{2} d x d y,
$$

where $\mathbb{C}_{\mathrm{i}}=\left\{(\mathrm{x}, \mathrm{y}) \in[0, \mathrm{c}] \times[0,1 / \mathrm{c}] \mid \quad\left(\mathrm{x}_{\mathrm{i}}-\mathrm{x}\right)^{2}+\left(\mathrm{y}_{\mathrm{i}}-\mathrm{y}\right)^{2} \leq\left(\mathrm{x}_{\mathrm{j}}-\mathrm{x}\right)^{2}+\left(\mathrm{y}_{\mathrm{j}}-\mathrm{y}\right)^{2}, \quad \mathrm{i} \neq \mathrm{j}\right\} . \quad$ As obtained earlier, Nash and Stackelberg equilibrium locations are given by $\left[\left(\mathrm{x}_{1}, \mathrm{y}_{1}\right),\left(\mathrm{x}_{2}, \mathrm{y}_{2}\right)\right]=[(0,1 / 2 \mathrm{c}),(\mathrm{c}, 1 / 2 \mathrm{c})]$ or $[(\mathrm{c} / 2,0),(\mathrm{c} / 2, \mathrm{c})]$. The welfare loss in either pair of locations is the same and calculated as $\mathcal{L}=\left(c^{2}+1 / c^{2}\right) / 12.5$ Obviously, this value increases 
as $c(\geq 1)$ gets large implying the greater loss in longer and more slender city.

On the other hand, the social optimum locations are easily calculated by differentiating (7) with respect to $x_{i}$ and $y_{i}$ respectively, and are given by $\left[\left(\mathrm{x}_{1}, \mathrm{y}_{1}\right),\left(\mathrm{x}_{2}, \mathrm{y}_{2}\right)\right]=[(\mathrm{c} / 4,1 / 2 \mathrm{c}),(3 \mathrm{c} / 4,1 / 2 \mathrm{c})]$ for $\mathrm{c} \geq 1$. The welfare loss is given by $\mathcal{L}=\left(\mathrm{c}^{2} / 4+1 / \mathrm{c}^{2}\right) / 12$. As before, this is also an increasing function of $\mathrm{c}$. Comparing these two values of $\mathcal{L}$, we can say that the welfare loss of Nash or Stackelberg equilibrium locations is 1.6 to 4 times as large as that of the social optimum locations, and that the loss ratio increases as the rectangle becomes long and slender. The welfare loss is 1.6 times in the square case, and 4 times with $\mathrm{c}$ infinite. The latter value becomes identical to that in the one-dimensional model, where the consumer distribution is uniform over a line segment.

The reason for the smaller gap between the optimum and equilibrium in the two-dimensional model would be understood in the following manner. Since the transportation cost is a square of the Euclidian distance, it can be decomposed into a square of the horizontal distance $\left(x_{i}-x\right)^{2}$ and a square of the vertical distance $\left(y_{i}-y\right)^{2}$. Integrating the former over $\mathbb{C}_{1} \in \mathbb{R}^{2}$ is equivalent to that over $\mathbb{C}_{1}^{\prime} \in \mathbb{R}$. However, there exists the other component of the distance cost $\left(\mathrm{y}_{\mathrm{i}}-\mathrm{y}\right)^{2}$ in the two-dimensional model. Since $\mathrm{y}_{1}=\mathrm{y}_{2}=1 / 2 \mathrm{c}$ are common in case of optimum and equilibrium, integration $\left(\mathrm{y}_{\mathrm{i}}-\mathrm{y}\right)^{2}$ over $\mathbb{C}_{1} \in \mathbb{R}^{2}$ in each case yields the same value. That is, whereas the loss ratio in the horizontal direction is 4 times, that in the vertical direction is one time. Putting the two components together, the loss ratio in the two-dimensional model becomes less than 4 times, which is the case for one-dimensional model. This opens the general question of applicability of the one-dimensional models to two-dimensional problems.

Finally, we note that the price competition in duopoly is so fierce that firms have to locate far apart in Nash or Stackelberg equilibrium, resulting in greater loss of welfare than the social optimum configuration. This is common to both dimensional cases. 


\section{CONCLUSIONS}

Throughout this paper, we have assumed that in two-dimensional plane there are two firms competing in location first and then in mill price under the quadratic transportation cost function of distance. Applying Caplin and Nalebuff (1991), we showed first that a unique Nash price equilibrium exists on a two-dimensional space for any pair of firm locations if the consumer distribution is uniform and is a convex set.

Second, we proved that if the convex set is given by any rectangle, then neither firm locates at the interior region in Nash two-stage (location then price) games. That is, the price competition which keeps their locations apart dominates the location competition which brings them near. This would explicate actual locational behavior of retail firms such as supermarkets which sell mostly identical commodities. Furthermore, we showed in the rectangular case that each firm locates at the midpoint of one side opposite to each other in Nash location equilibrium, and that multiple location equilibria exist when the rectangle is close to a square while a unique location equilibrium exists when the rectangle is long and slender (Proposition 2). It should be emphasized that although the price competition is so fierce that firms do not locate in the interior region, they do not necessarily locate to maximize the distance between the two. A similar result is obtained by Neven and Thisse (1990) although they consider horizontal and vertical differentiation instead of two dimensions of horizontal differentiation. We may interpret the result in a context of product characteristics space that firms maximize product differentiation in one characteristic while they minimize it in the other characteristic.

Third, we identified three factors in firms' location choice: (a) farther location to relax (Bertrand) price competition; (b) closer location to acquire customers; and (c) location which reduces the number of marginal customers. Factors $a$ and $b$ are frequently stated in the literature and hence need no explanation here. Factor $c$, on the other hand, never appears in one-dimensional models, but should be taken into account in analyzing two-dimensional models. This is because the number of marginal consumers, which is 
related to intensity of the price competition, varies according to their locations in a two-dimensional case, but not in a one-dimensional case. To put it plainly, firms can raise prices and hence profits when there are few marginal customers that firms want to acquire further (Remark 1).

Fourth, we modified the game of Nash location and Nash price to that of Stackelberg location and Nash price in Section 5. We obtained a unique Stackelberg location equilibrium for any rectangular (except square) uniform distribution of consumers (Proposition 3). Comparing it with the Nash one, we showed that the sequential choice of location is more desirable for the duopolistic firms than the simultaneous choice of location.

Finally, we computed the welfare loss defined by the sum of the transportation costs in the cases of Nash location equilibrium, Stackelberg location equilibrium and the social optimum for both one-dimensional space and two-dimensional space. We showed that the welfare loss of equilibrium locations in two-dimensional space is less than that in one-dimensional space. This casts some doubts on the use of one-dimensional models in evaluating the welfare loss of two-dimensional problems.

\section{APPENDIX}

\section{Proof of Lemma 1}

There are four cases below corresponding to Figure 2 (i)-(iv).

Case (i) $\left[c \leq x_{a}, 0 \leq x_{b} \leq c, 1 / c \leq y_{a}, 0 \leq y_{b} \leq 1 / c\right]$

The profits are respectively given by

$$
\Pi_{1}=\mathrm{p}_{1}\left[1-\left(\mathrm{c}-\mathrm{x}_{\mathrm{b}}\right)^{2} / 2 \alpha\right] \quad \text { and } \quad \Pi_{2}=\mathrm{p}_{2}\left(\mathrm{c}-\mathrm{x}_{\mathrm{b}}\right)^{2} / 2 \alpha \text {. }
$$

Calculating the first-order conditions of $\partial \Pi_{1} / \partial \mathrm{p}_{1}=0$ and $\partial \Pi_{2} / \partial \mathrm{p}_{2}=0$, we have

$$
\mathrm{p}_{1}^{*}=2 \alpha\left(\mathrm{x}_{2}-\mathrm{x}_{1}\right)\left[1 /\left(\mathrm{c}-\mathrm{x}_{\mathrm{b}}\right)-\left(\mathrm{c}-\mathrm{x}_{\mathrm{b}}\right) / 2 \alpha\right] \text { and } \mathrm{p}_{2}^{*}=\left(\mathrm{x}_{2}-\mathrm{x}_{1}\right)\left(\mathrm{c}-\mathrm{x}_{\mathrm{b}}\right) \text {. }
$$

Using (A1), $\Pi_{2}$ is rewritten as 


$$
\Pi_{2}^{*}=\frac{\mathrm{x}_{2}-\mathrm{x}_{1}}{2 \alpha}\left(\mathrm{c}-\mathrm{x}_{\mathrm{b}}\right)^{3} .
$$

Differentiating this with respect to $\mathrm{x}_{2}$,

$$
\frac{\partial \Pi_{2}^{*}}{\partial \mathrm{x}_{2}}=\frac{\left(\mathrm{c}-\mathrm{x}_{\mathrm{b}}\right)^{3}}{2 \alpha}-\frac{\mathrm{x}_{2}-\mathrm{x}_{1}}{2 \alpha^{2}}\left(\mathrm{c}-\mathrm{x}_{\mathrm{b}}\right)^{3} \frac{\partial \alpha}{\partial \mathrm{x}_{2}}-3 \frac{\mathrm{x}_{2}-\mathrm{x}_{1}}{2 \alpha}\left(\mathrm{c}-\mathrm{x}_{\mathrm{b}}\right)^{2} \frac{\partial \mathrm{x}_{\mathrm{b}}}{\partial \mathrm{x}_{2}} .
$$

The partial derivatives of the RHS in (A2) are given by

$$
\frac{\partial \alpha}{\partial \mathrm{x}_{2}}=\frac{-\alpha}{\mathrm{x}_{2}-\mathrm{x}_{1}} \quad \text { and } \quad \frac{\partial \mathrm{x}_{\mathrm{b}}}{\partial \mathrm{x}_{2}}=\frac{1}{\mathrm{x}_{2}-\mathrm{x}_{1}} \frac{\mathrm{x}_{2}+\mathrm{c}-2 \mathrm{x}_{\mathrm{b}}}{2+\alpha /\left(\mathrm{c}-\mathrm{x}_{\mathrm{b}}\right)^{2}} .
$$

The latter is obtained by substituting the prices of (A1) and the values of $(x, y)=\left(x_{b}, 1 / c\right)$ into equation (1), and applying the implicit theorem to it. (A2) is then rewritten as

$$
\begin{array}{rrr}
\frac{\partial \Pi_{2}^{*}}{\partial \mathrm{x}_{2}}=\frac{\left(\mathrm{c}-\mathrm{x}_{\mathrm{b}}\right)^{2}}{2 \alpha}\left[2\left(\mathrm{c}-\mathrm{x}_{\mathrm{b}}\right)-\frac{3\left(\mathrm{x}_{2}+\mathrm{c}-2 \mathrm{x}_{\mathrm{b}}\right)}{2+\alpha /\left(\mathrm{c}-\mathrm{x}_{\mathrm{b}}\right)^{2}}\right]>\frac{\left(\mathrm{c}-\mathrm{x}_{\mathrm{b}}\right)\left[\alpha-\left(\mathrm{c}-\mathrm{x}_{\mathrm{b}}\right)^{2}\right]}{\alpha\left[2+\alpha /\left(\mathrm{c}-\mathrm{x}_{\mathrm{b}}\right)^{2}\right]} \\
\geq \frac{\left(\mathrm{c}-\mathrm{x}_{\mathrm{b}}\right)^{2} \mathrm{x}_{\mathrm{b}}}{\alpha\left[2+\alpha /\left(\mathrm{c}-\mathrm{x}_{\mathrm{b}}\right)^{2}\right]} \geq 0 \quad \text { for all } \mathrm{x}_{2}<\mathrm{c} .
\end{array}
$$

The first inequality is implied by $x_{2}<c$, and the second is followed from $\alpha=\left(\mathrm{c}-\mathrm{x}_{\mathrm{b}}\right) /\left(1 / \mathrm{c}-\mathrm{y}_{\mathrm{b}}\right) \geq \mathrm{c}\left(\mathrm{c}-\mathrm{x}_{\mathrm{b}}\right)$. Note that if $\alpha \rightarrow+\infty$, then $\mathrm{x}_{1} \rightarrow \mathrm{x}_{2}$, which leads to $\mathrm{x}_{\mathrm{b}}<0$, i.e., $\alpha \rightarrow \infty$ does not correspond to case (i).

Similarly, we can show $\partial \Pi_{2}^{*} / \partial \mathrm{y}_{2}>0$ for all $\mathrm{y}_{2}<1 / \mathrm{c}$. Hence, firm 2 does not locate inside the rectangle, but rather locates at the corner $(c, 1 / c)$ in this market division case.

Case (ii) $\left[0 \leq x_{b} \leq x_{a} \leq c, 1 / c \leq y_{a}, y_{b} \leq 0\right]$

Each profit is given by

$$
\Pi_{1}=\mathrm{p}_{1}\left(\mathrm{x}_{\mathrm{a}}+\mathrm{x}_{\mathrm{b}}\right) / 2 \mathrm{c} \quad \text { and } \quad \Pi_{2}=\mathrm{p}_{2}\left[1-\left(\mathrm{x}_{\mathrm{a}}+\mathrm{x}_{\mathrm{b}}\right) / 2 \mathrm{c}\right] .
$$

Calculating $\partial \Pi_{1} / \partial \mathrm{p}_{1}=0$ and $\partial \Pi_{2} / \partial \mathrm{p}_{2}=0$, we get

$$
\Pi_{2}^{*}=\frac{\mathrm{x}_{2}-\mathrm{x}_{1}}{2 \mathrm{c}}\left(2 \mathrm{c}-\mathrm{x}_{\mathrm{a}}-\mathrm{x}_{\mathrm{b}}\right)^{2} \text {. }
$$

Differentiating this with respect to $\mathrm{x}_{2}$, we have

$$
\frac{\partial \Pi_{2}^{*}}{\partial \mathrm{x}_{2}}=\frac{2 \mathrm{c}-\mathrm{x}_{\mathrm{a}}-\mathrm{x}_{\mathrm{b}}}{2 \mathrm{c}}\left[4 \mathrm{c} / 3+\mathrm{x}_{1} / 3-\mathrm{x}_{2}+\alpha\left(\mathrm{y}_{1}+\mathrm{y}_{2}-1 / \mathrm{c}\right) / 3\right]
$$




$$
>\frac{2 \mathrm{c}-\mathrm{x}_{\mathrm{a}}-\mathrm{x}_{\mathrm{b}}}{6 \mathrm{c}}[\mathrm{c}-\alpha / \mathrm{c}] \geq 0 \quad \text { for all } \mathrm{x}_{2}<\mathrm{c} \text {. }
$$

The first inequality is followed from $\mathrm{x}_{2}<\mathrm{c}$ and $\mathrm{x}_{1}, \mathrm{y}_{1}, \mathrm{y}_{2} \geq 0$; and the second is due to the fact that the absolute value of the slope of equation (1) is greater than or equal to that of the diagonal of the rectangle, i.e., $|-1 / \alpha| \geq 1 / \mathrm{c}^{2}$.

Next, differentiating $\Pi_{2}^{*}$ with respect to $y_{2}$, we get

$$
\frac{\partial \Pi_{2}^{*}}{\partial \mathrm{y}_{2}}=\frac{2 \mathrm{c}-\mathrm{x}_{\mathrm{a}}-\mathrm{x}_{\mathrm{b}}}{3 \mathrm{c}}\left(1 / \mathrm{c}-2 \mathrm{y}_{2}\right)=0 \text {. }
$$

Therefore, the optimal location of firm 2 is the mid point of one side $(c, 1 / 2 c)$ in case (ii).

Case (iii) $\left[c \leq x_{a}, x_{b} \leq 0,0 \leq y_{b} \leq y_{a} \leq 1 / c\right]$

Similar computation as in case (ii), we obtain that

$$
\frac{\partial \Pi_{2}^{*}}{\partial \mathrm{x}_{2}}=\mathrm{c}\left(2 / \mathrm{c}-\mathrm{y}_{\mathrm{a}}-\mathrm{y}_{\mathrm{b}}\right)\left(\mathrm{c}-2 \mathrm{x}_{2}\right) / 3=0 \quad \text { and } \quad \frac{\partial \Pi_{2}^{*}}{\partial \mathrm{y}_{2}}>0 \quad \text { for all } \mathrm{y}_{2}<1 / \mathrm{c} \text {. }
$$

That is, the optimal location of firm 2 is the midpoint of one side $(c / 2,1 / c)$.

Case (iv) $\left[0 \leq x_{a} \leq c, x_{b} \leq 0,0 \leq y_{b} \leq 1 / c, y_{b} \leq 0\right]$

Similar calculations as in case (i) yield $\partial \Pi_{1}^{*} / \partial \mathrm{x}_{1}<0$ for all $\mathrm{x}_{1}>0$, and $\partial \Pi_{1}^{*} / \partial \mathrm{y}_{1}<0$ for all $\mathrm{y}_{1}>0$. Thus, the optimal location of firm 1 is the corner $(0,0)$.

\section{Proof of Lemma 2}

Let $\left(x_{1}, y_{1}\right)=(0,0)$ and $c \geq 1$ without loss of generality. We will compute the equilibrium profits of firm 2 corresponding to the four cases appeared in Lemma 1.

\section{Case (i)}

From Lemma 1(i), we have $\left(\mathrm{x}_{2}^{*}, \mathrm{y}_{2}^{*}\right)=(\mathrm{c}, 1 / \mathrm{c})$ iff $\mathrm{c}=1$. (If $\mathrm{c} \neq 1$, case(i) does not occur.) The corresponding profit is $\Pi_{2}^{*_{i}}=1 / 2$.

Case (ii)

From Lemma $1\left(\right.$ ii), we have $\left(\mathrm{x}_{2}^{*}, \mathrm{y}_{2}^{*}\right)=(\mathrm{c}, 1 / 2 \mathrm{c})$. The corresponding profit is 
$\Pi_{2}^{*}{ }_{\mathrm{ii}}=\left(12 \mathrm{c}+1 / \mathrm{c}^{3}\right)^{2} / 288 \geq 169 / 288$ since $\mathrm{c} \geq 1$.

Case (iii)

From Lemma $1(\mathrm{iii})$, we have $\left(\mathrm{x}_{2}^{*}, \mathrm{y}_{2}^{*}\right)=(\mathrm{c} / 2,1 / \mathrm{c})$ and $\Pi_{2}^{*}{ }^{*}{ }^{\mathrm{iii}}=\left(12 / \mathrm{c}+\mathrm{c}^{3}\right)^{2} / 288 \leq$ $169 / 288$ since $c \geq 1$.

Case (iv)

Calculating $\partial \Pi_{2}^{*} / \partial \mathrm{x}_{2}=0$ and $\partial \Pi_{2}^{*} / \partial \mathrm{y}_{2}=0$, and substituting $\mathrm{x}_{1}=\mathrm{y}_{1}=0$, we get

$$
\begin{gathered}
2\left(\mathrm{x}_{\mathrm{a}}-\mathrm{x}_{2}\right)\left(2+\alpha / \mathrm{x}_{\mathrm{a}}^{2}\right)+\mathrm{x}_{2}-2 \mathrm{x}_{\mathrm{a}}=0 \\
\left(\mathrm{x}_{\mathrm{a}} / \alpha-2 \alpha \mathrm{x}_{2}\right)\left(2+\alpha / \mathrm{x}_{\mathrm{a}}^{2}\right)+1 / \mathrm{x}_{\mathrm{a}}+\alpha \mathrm{x}_{2}=0 .
\end{gathered}
$$

Subtracting (A4) from (A3) multiplied by $\alpha$, we have

$$
\left(\alpha^{2}-1\right)\left(1 / \alpha+1 / x_{a}^{2}\right)=0
$$

Thus, $\alpha$ should be unity in equilibrium in case (iv), and so $\mathrm{x}_{2}^{*}=\mathrm{y}_{2}^{*}$.

Moreover, using $\partial \Pi_{1} / \partial \mathrm{p}_{1}=0, \partial \Pi_{2} / \partial \mathrm{p}_{2}=0$ and the definition of $\mathrm{x}_{\mathrm{a}}$, we obtain

$$
\mathrm{x}_{2}^{*}=2 \mathrm{x}_{\mathrm{a}}^{*}-1 / \mathrm{x}_{\mathrm{a}}^{*}
$$

From (A3) and (A5), we finally get $\mathrm{x}_{2}^{*}=\mathrm{y}_{2}^{*}=(\sqrt{33}-3) / \sqrt{2 \sqrt{33}+2}$ and $\Pi_{2}^{* \mathrm{iV}}=(207-33 \sqrt{33}) / 32$, for $c \leq \sqrt{2 \sqrt{33}+2} /(\sqrt{33}-3)$. For $c>\sqrt{2 \sqrt{33}+2} /(\sqrt{33}-3)$, we have $x_{2}=1 / c$, which does not satisfy the first-order condition. This implies that $\Pi_{2}^{*}$ iv for $c>\sqrt{2 \sqrt{33}+2} /(\sqrt{33}-3)$ is smaller than $\Pi_{2}^{*}{ }^{\mathrm{iv}}$ for $c \leq \sqrt{2 \sqrt{33}+2} /(\sqrt{33}-3)$

Comparing the above four values of $\Pi_{2}^{*}$, we conclude that $\Pi_{2}^{*_{\mathrm{ii}}}$ is the largest.

\section{Proof of Lemma 3}

Let $\left(\mathrm{x}_{1}, \mathrm{y}_{1}\right)=(0,1 / 2 \mathrm{c})$, where $c \in(0, \infty)$ without loss of generality. Similar to the previous lemma, we compute the equilibrium profits of firm 2 for the four cases.

Case (i)

If this is the case, firm 2 locates at $(c, 1 / c)$ from Lemma $1(i)$. The condition of $y_{b} \geq 0$ 
is satisfied if $c \leq(7 / 12)^{1 / 4}$, and the condition of $x_{b} \geq 0$ is satisfied if $c \geq(5 / 12)^{1 / 4}$. That is, $\Pi_{2}^{*}{ }_{i}=\left[c^{2}+1 / 4 c^{2}+\sqrt{\left(c^{2}+1 / 4 c^{2}\right)^{2}+16}\right]^{3} / 512$ iff $c \in\left((5 / 12)^{1 / 4},(7 / 12)^{1 / 4}\right)$. Otherwise, case (i) is not applied. This result is valid too when firm 2 locates at $(c, 0)$.

Case (ii)

From Lemma 1(ii), firm 2 locates at $(c, 1 / 2 c)$, and earns the profit of $\Pi_{2}^{* i i}=c^{2} / 2$. Of course, the conditions of $0 \leq x_{a}, x_{b} \leq c$ are satisfied for all $c>0$ since $x_{a}=x_{b}=c / 2$.

Case (iii)

From Lemma 1(iii), firm 2 locates at $(\mathrm{c} / 2,1 / \mathrm{c})$. Its profit is given by $\Pi_{2}^{*}{ }^{* i i}=\left(c^{3}+5 / c\right)^{2} / 144$ iff $c \leq 1$. This result also applies when firm 2 locates at $(c / 2,0)$.

Case (iv)

This case does not occur because of the following reason. $x_{b} \leq c$ holds for $c \geq(7 / 12)^{1 / 4}$, and $y_{b} \leq 1 / c$ holds for $c \leq(5 / 12)^{1 / 4}$. This means that both $x_{b} \leq c$ and $y_{b} \leq 1 / c$ are not simultaneously satisfied when locations of the two firms are $(0,1 / 2 c)$ and $(c, 1 / c)$.

Consider first the comparison between $\Pi_{2}^{*_{i}}$ and $\Pi_{2}^{*_{i i}}$ for all $c \in\left((5 / 12)^{1 / 4},(7 / 12)^{1 / 4}\right)$ since $\Pi_{2}^{*_{\mathrm{i}}}$ is defined only within this interval. As $\Pi_{2}^{*_{\mathrm{i}}}$ and $\Pi_{2}^{*_{\mathrm{ii}}}$ are increasing for all $\operatorname{c\in }\left((5 / 12)^{1 / 4},(7 / 12)^{1 / 4}\right)$, and as $\Pi_{2}^{*_{\mathrm{i}}}$ at $c=(7 / 12)^{1 / 4}$ is strictly less than $\Pi_{2}^{*_{\mathrm{ii}}}$ at $\mathrm{c}=(5 / 12)^{1 / 4}$, we conclude $\Pi_{2}^{*_{\mathrm{ii}}}>\Pi_{2}^{*_{\mathrm{i}}}$ for all $\mathrm{c} \in\left((5 / 12)^{1 / 4},(7 / 12)^{1 / 4}\right)$. That is, we can drop case (i) as a candidate for firm 2's best locational reply, which gives a proof of the former part of Lemma 3.

The latter part of Lemma 3 can be shown by comparing $\Pi_{2}^{*_{\mathrm{ii}}}$ with $\Pi_{2}^{*_{\mathrm{iii}}}$ for $\mathrm{c} \leq 1$. Taking the root and subtracting, we have $\sqrt{\mathrm{H}_{2}^{\text {कiI }}}-\sqrt{\mathrm{\Pi}_{2}^{\text {सil }}}=\left(c^{4}-6 \sqrt{2} c^{2}+5\right) /(12 c)$, which is

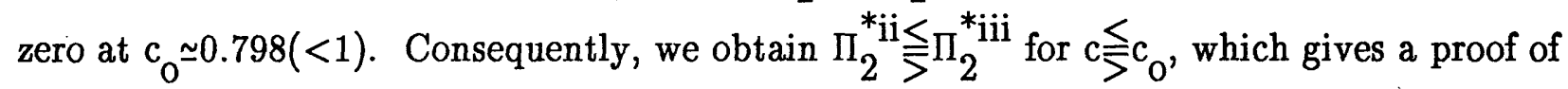
the latter part.

\section{Proof of Proposition 2}


From Lemmas 1 and 2, we know that one firm should locate at a midpoint of one side.

(a) $c<c_{0}$

Suppose firm 1 locates at $(0,1 / 2 c)$. Then, firm 2 will locate at $(c / 2,1 / c)$ from Lemma 3. Conversely, however, $(0,1 / 2 \mathrm{c})$ of firm 1 's location is not the best reply against $(\mathrm{c} / 2,1 / \mathrm{c})$ of firm 2 's location due to the following reason. If we rotate the rectangle by $\pi / 2$, the side lengths become $1 / \mathrm{c}$ by $\mathrm{c}$, and $\mathrm{c}_{0}$ is replaced with $1 / \mathrm{c}_{0}$, which is of course greater than $c_{0}$. Hence, the best reply of firm 1 is not $(0,1 / 2 c)$, but $(c / 2,0)$ from Lemma 3 . On the other hand, if firm 1 locates at $(c / 2,0)$, then firm 2 locates at $(c / 2,1 / c)$ due to symmetry.

(b) $c_{0} \leq c \leq 1$

If firm 1 locates at $(0,1 / 2 c)$, then firm 2 locates at $(c, 1 / 2 c)$ from Lemma 3. By symmetry, the reverse is also true. Similarly, if firm 1 locates at $(c / 2,0)$, then firm 2 locates at $(\mathrm{c} / 2,1 / \mathrm{c})$, and the reverse is true too.

\section{Proof of Lemma \&}

Without losing generality, assume $c \geq 1$.

\section{Case (ii)}

$$
\begin{aligned}
& \text { Differentiating } \Pi_{1}^{* i i} \text { with respect to } \mathrm{x}_{2} \text {, we have } \\
& \qquad \begin{aligned}
\frac{\partial \Pi_{1}^{*}{ }_{\mathrm{ii}}}{\partial \mathrm{x}_{2}}= & \frac{\mathrm{x}_{\mathrm{a}}+\mathrm{x}_{\mathrm{b}}}{6 \mathrm{c}}\left[3 \mathrm{x}_{2}-\mathrm{x}_{1}+\frac{\mathrm{y}_{2}-\mathrm{y}_{1}}{\mathrm{c}\left(\mathrm{x}_{2}-\mathrm{x}_{1}\right)}+2 \mathrm{c}-\frac{\mathrm{y}_{2}-\mathrm{y}_{1}}{\mathrm{x}_{2}-\mathrm{x}_{1}}\left(\mathrm{y}_{1}+\mathrm{y}_{2}\right)\right] \\
& \geq \frac{\mathrm{x}_{\mathrm{a}}+\mathrm{x}_{\mathrm{b}}}{6 \mathrm{c}}\left[3 \mathrm{x}_{2}-\mathrm{x}_{1}+\frac{\mathrm{y}_{2}-\mathrm{y}_{1}}{\mathrm{c}\left(\mathrm{x}_{2}-\mathrm{x}_{1}\right)}+\mathrm{c}\left(2-\mathrm{cy}_{1}-\mathrm{cy}_{2}\right)\right]
\end{aligned}
\end{aligned}
$$

since $\left(\mathrm{y}_{2}-\mathrm{y}_{1}\right) /\left(\mathrm{x}_{2}-\mathrm{x}_{1}\right) \leq \mathrm{c}^{2}$. As $\mathrm{y}_{1}, \mathrm{y}_{2} \leq 1 / \mathrm{c}$, the last term in the brackets is nonnegative, and hence $\partial \Pi_{1}^{*} / \partial x_{2} \geq 0$. If the equality were to hold, then $x_{1}=x_{2}=0$, which does not occur in case (ii). Thus, we conclude $\partial \Pi_{1}^{*}{ }^{i i} / \partial \mathrm{x}_{2}>0$.

Next, differentiating $\Pi_{1}^{*_{\mathrm{ii}}}$ with respect to $\mathrm{y}_{2}$, we obtain 


$$
\frac{\partial \Pi_{1}^{* i i}}{\partial \mathrm{y}_{2}}=\frac{\mathrm{x}_{\mathrm{a}}+\mathrm{x}_{\mathrm{b}}}{3 \mathrm{c}}\left(2 \mathrm{y}_{2}-1 / \mathrm{c}\right) .
$$

This means that $\partial \Pi_{1}^{* i i} / \partial y_{2} \gtreqless 0$ for $y_{2} \gtreqless 1 / 2$ c.

Case (iii)

The same operation as above yields $\partial \Pi_{1}^{*}{ }^{* i i i} / \partial \mathrm{x}_{2} \underset{\gtrless}{\gtrless}$ for $\mathrm{x}_{2} \underset{2}{\gtrless} \mathrm{c} / 2$, and $\partial \Pi_{1}^{*}{ }^{i i i} / \partial \mathrm{y}_{2}>0$.

\section{Case (iv)}

Differentiating $\Pi_{1}^{* i v}$ with respect to $x_{2}$ and manipulating, we have

$$
\frac{\partial \Pi_{1}^{*} \mathrm{iv}}{\partial \mathrm{x}_{2}}=\frac{\left(\mathrm{x}_{2}-\mathrm{x}_{1}\right)^{2} \mathrm{x}_{\mathrm{a}}^{2}\left[3 \mathrm{x}_{2}+2\left(1-\mathrm{x}_{\mathrm{a}} \mathrm{y}_{\mathrm{a}}\right) / \mathrm{y}_{\mathrm{a}}\right]}{2\left(\mathrm{y}_{2}-\mathrm{y}_{1}\right)\left[2\left(\mathrm{x}_{2}-\mathrm{x}_{1}\right)+\left(\mathrm{y}_{2}-\mathrm{y}_{1}\right) / \mathrm{x}_{\mathrm{a}}^{2}\right]}>0
$$

since $\mathrm{x}_{\mathrm{a}}, \mathrm{y}_{\mathrm{a}} \leq 1$ and $\mathrm{x}_{2}>\mathrm{x}_{1}$. [ $\mathrm{x}_{1}=\mathrm{x}_{2}$ does not occur in case(iv)].

$\partial \Pi_{1}^{* i \mathrm{iv}} / \partial \mathrm{y}_{2}>0$ can be shown by similar calculations.

\section{Proof of Lemma 5}

As the midpoint and the corner are the only possibilities for firm 2, it suffices to prove that the former is preferred to the latter for all c. So, consider case (i), where firm 2 necessarily locates at a corner $O(0,0) \cdot 6$

Then, the maximum profit that firm 1 could obtain is $(207-33 \sqrt{33}) / 32$ from Lemma 2(iv) (with permutation of firm indices). On the other hand, if firm 1 located at the midpoint of the short side, then firm 2 would locate at the opposite midpoint of the short side, and hence firm 1 earns the profit that is $\max \left\{\mathrm{c}^{2} / 2,1 / 2 \mathrm{c}^{2}\right\}$ from Lemma 3 (ii). Comparing these profits, it might be possible for firm 2 to locate at a corner only when $c \in\left(c_{1}^{-1}, c_{1}\right)$, where $c_{1} \equiv \sqrt{(207-33 \sqrt{33}) / 16} \simeq 1.05$.

Now, if firm 2 locates at $\mathrm{O}$ in Figure 3, then

$$
\mathrm{y}_{\mathrm{a}}=\frac{1}{8 \mathrm{x}_{1}}\left[\mathrm{x}_{1}^{2}+\mathrm{y}_{1}^{2}+\sqrt{\left(\mathrm{x}_{1}^{2}+\mathrm{y}_{1}^{2}\right)^{2}+32 \mathrm{x}_{1} \mathrm{y}_{1}}\right] \leq \frac{1}{\mathrm{c}}
$$

is necessary to hold so that case (iv) applies. That is, the location of firm 1 is in $\mathbb{C}_{2}$, where

$$
\mathbb{C}_{2}=\left\{\left(\mathrm{x}_{1}, \mathrm{y}_{1}\right) \mid\left(\mathrm{x}_{1}+\mathrm{c}\right)^{2}+\left(\mathrm{y}_{1}-2 / \mathrm{c}\right)^{2} \leq \mathrm{c}^{2}+4 / \mathrm{c}^{2}, \mathrm{c} / 2 \leq \mathrm{x}_{1} \leq \mathrm{c}, 1 / 2 \mathrm{c} \leq \mathrm{y}_{1} \leq 1 / \mathrm{c}, \mathrm{y}_{1} \leq \mathrm{x}_{1}\right\} .
$$


The last inequality does not lose generality due to the symmetric nature of rectangles. In other words, the case of $y_{1}>x_{1}$ can be similarly shown by interchanging $c$ with $c^{-1}$ in the proof below. Thus, confining firm 1's location to $\mathbb{C}_{2}$ (which is the shaded area in Figure 3 ), and limiting the range of one side to $\left(c_{1}^{-1}, c_{1}\right)$, we will prove that for any firm 1 's location within the shaded area, firm 2 is sure to locate at $A(0,1 / 2 c)$, but not at $O(0,0)$.

\section{[Figure 3 about here]}

\section{(2) For $c \geq 1$}

As $\mathrm{x}_{1}>1$ does not satisfy the first inequality in $\mathbb{C}_{1}$ for $\mathrm{c} \geq 1$, we can limit the range of $\mathrm{x}_{1}$ to $[\mathrm{c} / 2,1]$. From (5) in Lemma 4, firm 2's profit at $\mathrm{A}$ is smaller if firm 1 is at $\mathrm{R}\left(\mathrm{x}_{1}, 1 / 2 \mathrm{c}\right)$ rather than at $\mathrm{P}\left(\mathrm{x}_{1}, \mathrm{y}_{1}\right)$, i.e., for $\mathrm{y}_{1} \geq 1 / 2 \mathrm{c}$,

$$
\Pi_{2}^{*}{ }_{2}^{\mathrm{ii}}\left(\mathrm{x}_{1}, \mathrm{y}_{1}, 0,1 / 2 \mathrm{c}\right) \geq \Pi_{2}^{*} \mathrm{ii}\left(\mathrm{x}_{1}, 1 / 2 \mathrm{c}, 0,1 / 2 \mathrm{c}\right)=\frac{\mathrm{x}_{1}}{18 \mathrm{c}}\left(\mathrm{x}_{1}+2 \mathrm{c}\right)^{2} .
$$

On the other hand, from (6) in Lemma 4, firm 2's profit at $O$ is larger if firm 1 is at $\mathrm{Q}\left(\mathrm{x}_{1}, \mathrm{x}_{1}\right)$ rather than at $\mathrm{P}\left(\mathrm{x}_{1}, \mathrm{y}_{1}\right)$, i.e., for $\mathrm{y}_{1} \leq \mathrm{x}_{1}$,

$$
\Pi_{2}^{* i v}\left(x_{1}, y_{1}, 0,0\right) \leq \Pi_{2}^{* i v}\left(x_{1}, x_{1}, 0,0\right)=\frac{x_{1}}{128}\left(x_{1}+\sqrt{x_{1}^{2}+8}\right)^{3} .
$$

By comparing (A6) with (A7), we can say that $\mathrm{A}$ is preferred to $\mathrm{O}$ by firm 2, [i.e., $\left.\Pi_{2}^{*} \mathrm{ii}_{1}\left(\mathrm{x}_{1}, \mathrm{y}_{1}, 0,1 / 2 \mathrm{c}\right)>\Pi_{2}^{*} \mathrm{iv}^{\mathrm{v}}\left(\mathrm{x}_{1}, \mathrm{y}_{1}, 0,0\right)\right]$ if $\psi\left(\mathrm{x}_{1}\right)>0$ for all $\mathrm{x}_{1} \in \mathbb{C}_{1}$ and $c \in\left[1, \mathrm{c}_{1}\right)$, where

$$
\psi\left(\mathrm{x}_{1}\right) \equiv \mathrm{x}_{1}+2 \mathrm{c}-3 \sqrt{\mathrm{c}}\left(\mathrm{x}_{1}+3\right)^{3 / 2} / 8 \text {. }
$$

Since a simple calculation yields that $\psi^{\prime \prime}\left(\mathrm{x}_{1}\right)<0, \psi^{\prime}(1 / 2)<0$ and $\psi(1)>0$, we have $\psi\left(\mathrm{x}_{1}\right)>0$, which means that $\mathrm{A}$ is preferred to $\mathrm{O}$ by firm 2 .

(2) For $\mathrm{c}<1$

We divide the range of $x_{1}$ into the following two intervals.

[2a] $1 / 2 c \leq x_{1} \leq 1 / 2 c+1 / 4$

As $\quad \psi^{\prime \prime}\left(\mathrm{x}_{1}\right)<0, \quad \psi^{\prime}(1 / 2)<0$ and $\psi(1 / 2 \mathrm{c}+1 / 4)>0 \quad \forall c \in\left(\mathrm{c}_{1}^{-1}, 1\right)$, we have $\psi\left(\mathrm{x}_{1}\right)>0$, implying that $A$ is preferred to $O$ by firm 2 for $x_{1} \in[1 / 2 c, 1 / 2 c+1 / 4]$. 


\section{[2b] $1 / 2 c+1 / 4 \leq \mathrm{x}_{1} \leq \mathrm{c}$}

Consider the line $y=x-1 / 4$, which is shown to be outside $\mathbb{C}_{1}$ for $x \geq 1 / 2 c+1 / 4$. Therefore, again from (5) in Lemma 4, firm 2's profit at $A$ is smaller if firm 1 is at $\mathrm{S}\left(\mathrm{x}_{1}, \mathrm{x}_{1}-1 / 4\right)$ rather than at $\mathrm{P}\left(\mathrm{x}_{1}, \mathrm{y}_{1}\right)$, i.e.,

$$
\begin{aligned}
\Pi_{2}^{*} \mathrm{ii}_{1}\left(\mathrm{x}_{1}, \mathrm{y}_{1}, 0,1 / 2 \mathrm{c}\right) & \geq \Pi_{2}^{*}{ }_{\mathrm{ii}}\left(\mathrm{x}_{1}, \mathrm{x}_{1}-1 / 4,0,1 / 2 \mathrm{c}\right) \\
& =\frac{1}{18 \mathrm{cx}}\left[2 \mathrm{x}_{1}^{2}+(2 \mathrm{c}-1 / 2-1 / \mathrm{c}) \mathrm{x}_{1}+\left(1 / 16+1 / 4 \mathrm{c}+1 / 4 \mathrm{c}^{2}\right)\right]^{2} .
\end{aligned}
$$

By comparing (A7) with (A8), we can say that $\mathrm{A}$ is preferred to $\mathrm{O}$ by firm 2, [i.e., $\left.\Pi_{2}^{*}{ }^{* i i}\left(x_{1}, y_{1}, 0,1 / 2 c\right)>\Pi_{2}^{*}{ }^{*}\left(x_{1}, y_{1}, 0,0\right)\right]$ if $\phi\left(x_{1}\right)>0$ for all $x_{1} \in \mathbb{C}_{1}$ and $c \in\left(c_{1}^{-1}, 1\right)$, where

$$
\phi\left(\mathrm{x}_{1}\right) \equiv 2 \mathrm{x}_{1}^{2}+(2 \mathrm{c}-1 / 2-1 / \mathrm{c}) \mathrm{x}_{1}+1 / 16+1 / 4 \mathrm{c}+1 / 4 \mathrm{c}^{2}-3 \sqrt{\mathrm{c}} \mathrm{x}_{1}\left(\mathrm{x}_{1}+3\right)^{3 / 2} / 8 \text {. }
$$

After some computations, we get $\phi^{\prime \prime \prime}\left(\mathrm{x}_{1}\right)<0, \phi^{\prime \prime}(1)>0, \phi^{\prime}(1)<0$ and $\phi(1)>0$ for all $c \in\left(c_{1}^{-1}, 1\right)$. Hence, $\phi\left(x_{1}\right)>0$, which means that $A$ is preferred to $O$ by firm 2 for $\mathrm{x}_{1} \in[1 / 2 \mathrm{c}+1 / 4, \mathrm{c}]$.

\section{Proof of Proposition 5}

According to Lemma 5 , firm 2 (the follower) necessarily chooses to locate at the midpoint. Knowing this and from Lemma 1, firm 1 would locate at a midpoint or a corner.

Assume $c \geq 1$ without losing generality. If firm 1 chooses to locate at $(0,0)$, then firm 2 chooses $(c, 1 / 2 c)$ from Lemma 2 , and $\Pi_{1}^{*}=\left(3 c-1 / 4 c^{3}\right)^{2} / 18$. On the other hand, if firm 1 locates at $(0,1 / 2 c)$, which is the midpoint of the short side, then firm 2 chooses (c,1/2c) from Lemma 3 , and so $\Pi_{1}^{*}=c^{2} / 2$. Obviously, the latter profit is greater than the former. Moreover, if firm 1 were to locate at the midpoint of the long side, it is definitely inferior than that of the short side.

\section{FOOTNOTES}


* This research was supported by the Japanese Overseas Research Fellowship of Ministry of Education and the CORE grant at Université Catholique de Louvain. An earlier version of this paper was presented at the Research Institute for Economics and Business Administration of Kobe University. I wish to thank the participants, Jacques Thisse, and an anonymous referee for invaluable comments.

$1 \quad$ For example, suppose the transportation cost is proportional to a power of distance. Then, the nonexistence of price equilibrium occurs for any power except 2 when firms locate sufficiently close.

2 This is also true for the case of uniform ellipse distributions of consumers. According to our numerical analysis, the two-stage Nash equilibrium locations are computed as:

$$
\begin{aligned}
\left(\mathrm{x}_{1}^{*}, \mathrm{y}_{1}^{*}, \mathrm{x}_{2}, \mathrm{y}_{2}^{*}\right. & =(\mathrm{a}, 0,-\mathrm{a}, 0) & & \text { for } 1<\mathrm{a} / \mathrm{b}<1.36 \\
& =(\mathrm{a}, 0,-\mathrm{a}, 0) \text { or }(0, \mathrm{~b}, 0,-\mathrm{b}) & & \text { for } \mathrm{a} / \mathrm{b} \geq 1.36
\end{aligned}
$$

where the ellipse is given by $x^{2} / a^{2}+y^{2} / b^{2}=1$.

3 We also proved that the exclusion of interior location holds under any uniform ellipse distribution of consumers. In case of a disc, the two-stage Nash equilibrium locations are shown to be opposite points on the circumference. Proofs of these results are omitted here to save space, but are contained in Tabuchi (1990).

4 Since both Nash and Stackelberg equilibrium locations are found to be symmetric, the prices are same, and hence consumers necessarily go to their nearest firm.

$5 \quad$ Although there is no difference between Nash and Stackelberg equilibrium locations in terms of the welfare loss, the producer's surplus (i.e., the profit) differs between the two 
as is seen in Section 5 .

6 To simplify mathematical computations, firm 2's location is set to $(0,0)$ instead of $(\mathrm{c}, 1 / \mathrm{c})$ in this proof.

\section{REFERENCES}

Caplin, Andrew and Barry Nalebuff, 1991, Aggregation and imperfect competition: On the existence of equilibrium, Econometrica 59, 25-59.

Champsaur, Paul and Jean-Charles Rochet, 1988, Existence of a price equilibrium in a differentiated industry, Discussion Paper No.8801, INSEE.

d'Aspremont, Claude, J. Jaskold Gabszewicz and Jacques-François Thisse, 1979, On Hotelling's "Stability in Competition," Econometrica 47, 1145-1150.

Economides, Nicholas, 1986, Nash equilibrium in duopoly with products defined by two characteristics, Rand Journal of Economics, 17, 431-439.

Hotelling, Harold, 1929, Stability in competition, Economic Journal 39, 41-57.

Neven, Damien and Jacques-François Thisse, 1990, On quality and variety competition, in: J.J. Gabszewicz, J.-F. Richard and L.A. Wolsey eds., Economic Decision Making: Games, Econometrics and Optimisation: Contributions in Honour of J. Drèze (North-Holland, Amsterdam).

Shaked, Avner, 1975, Non-existence of equilibrium for the two-dimensional three-firms location problem, Review of Economic Studies 42, 51-56.

Tabuchi, Takatoshi, 1990, Two-stage two-dimensional spatial competition between two firms, Discussion Paper No.424, Institute of Socio-Economic Planning, University of Tsukuba. 


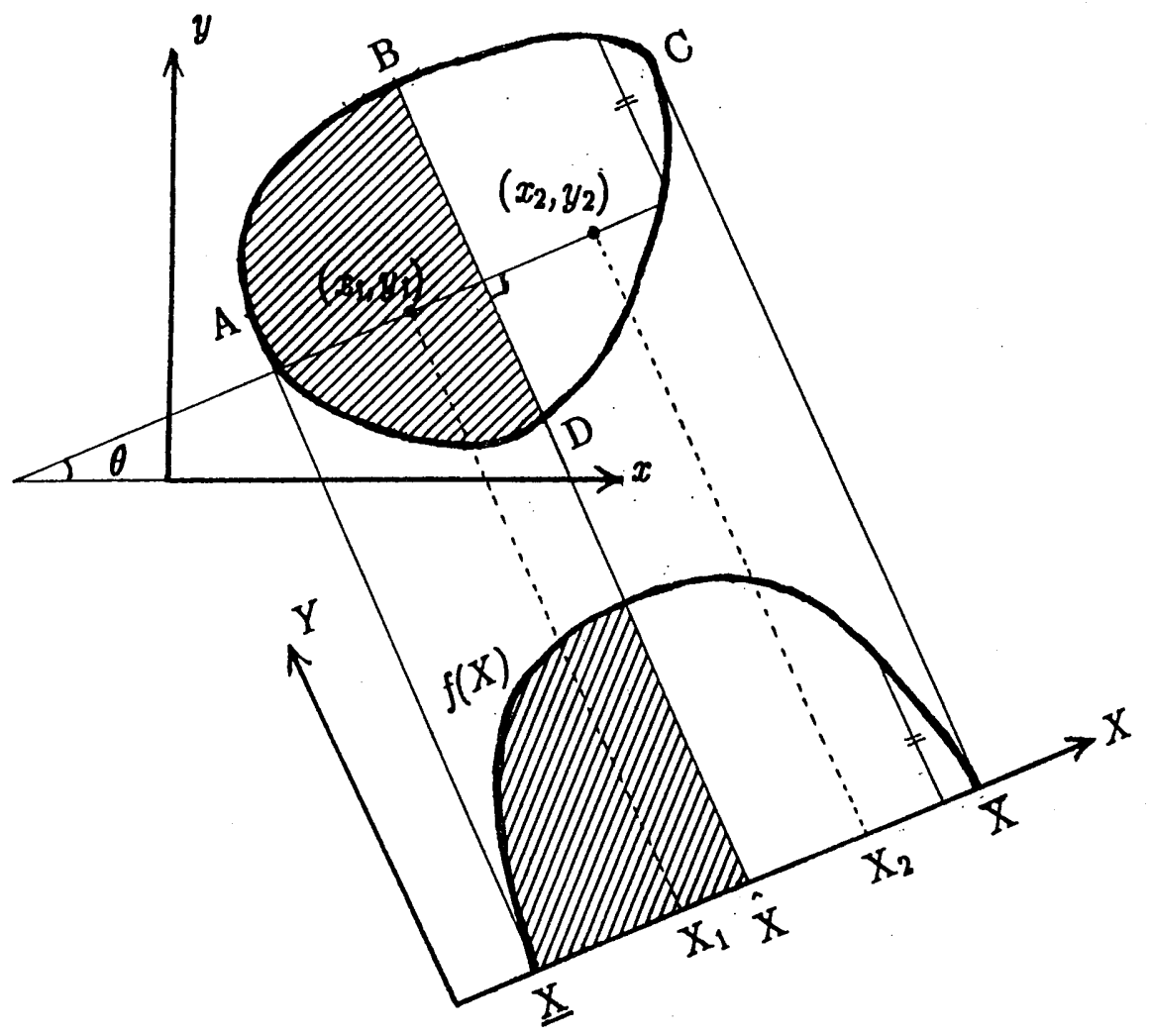

Figure 1 Conversion of two-dimensional uniform distribution over a convex set into one-dimensional concave distribution 

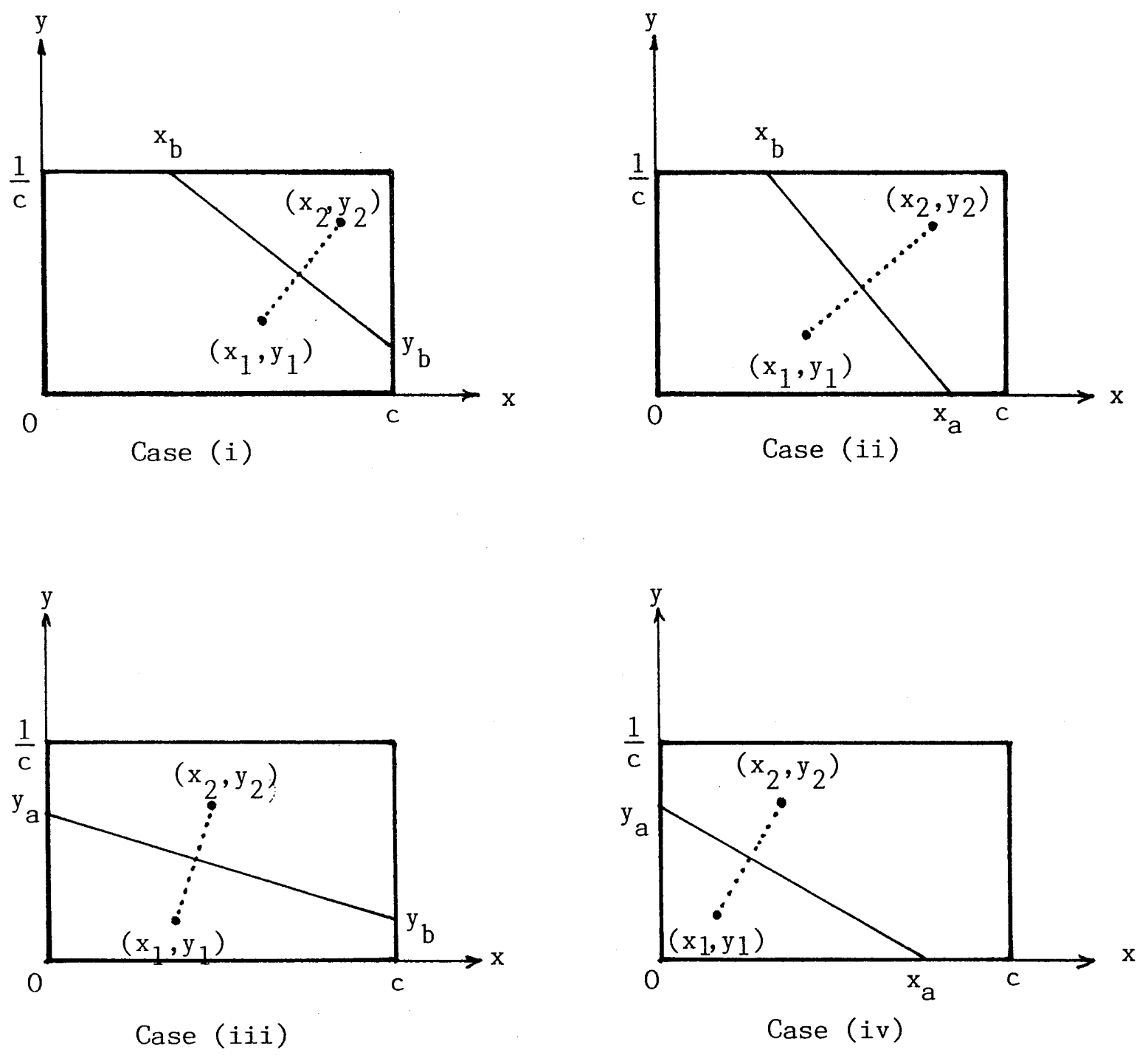

Figure 2 Four cases of market division under a rectangular distribution of consumers 


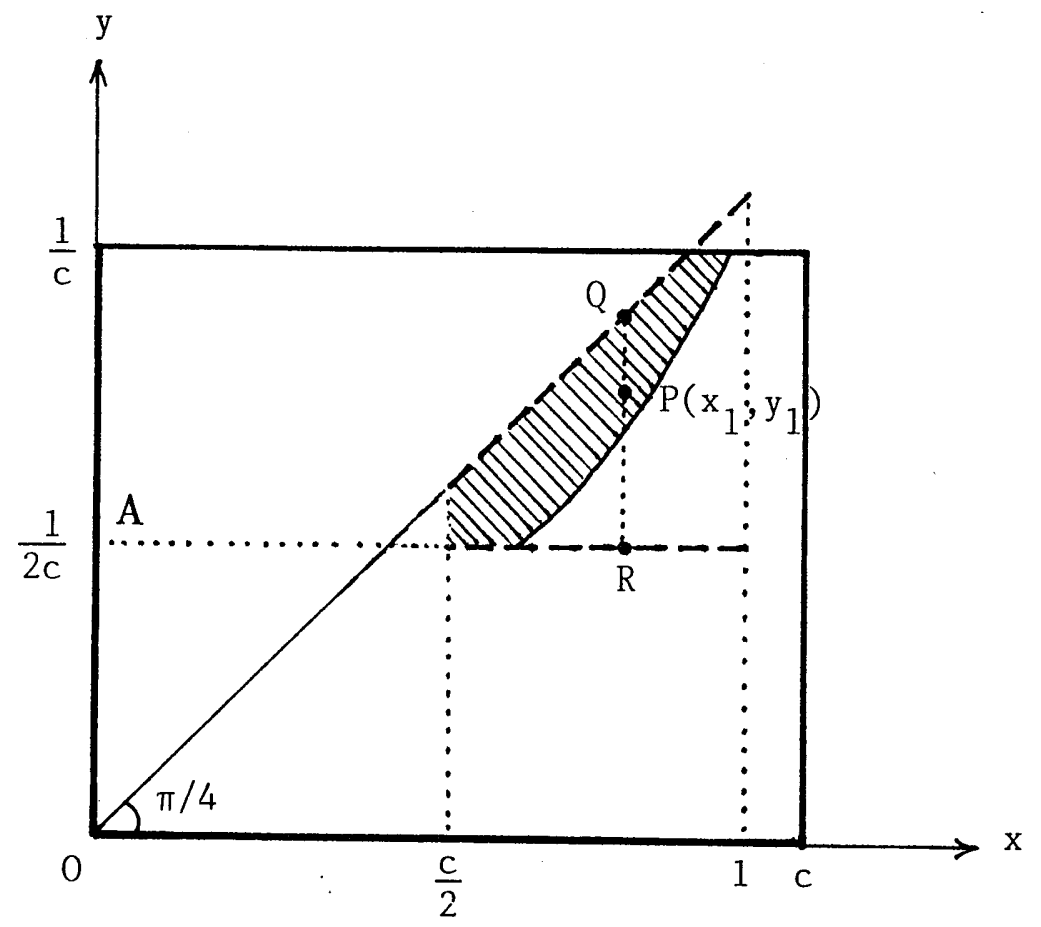

(1) $c \geqq 1$

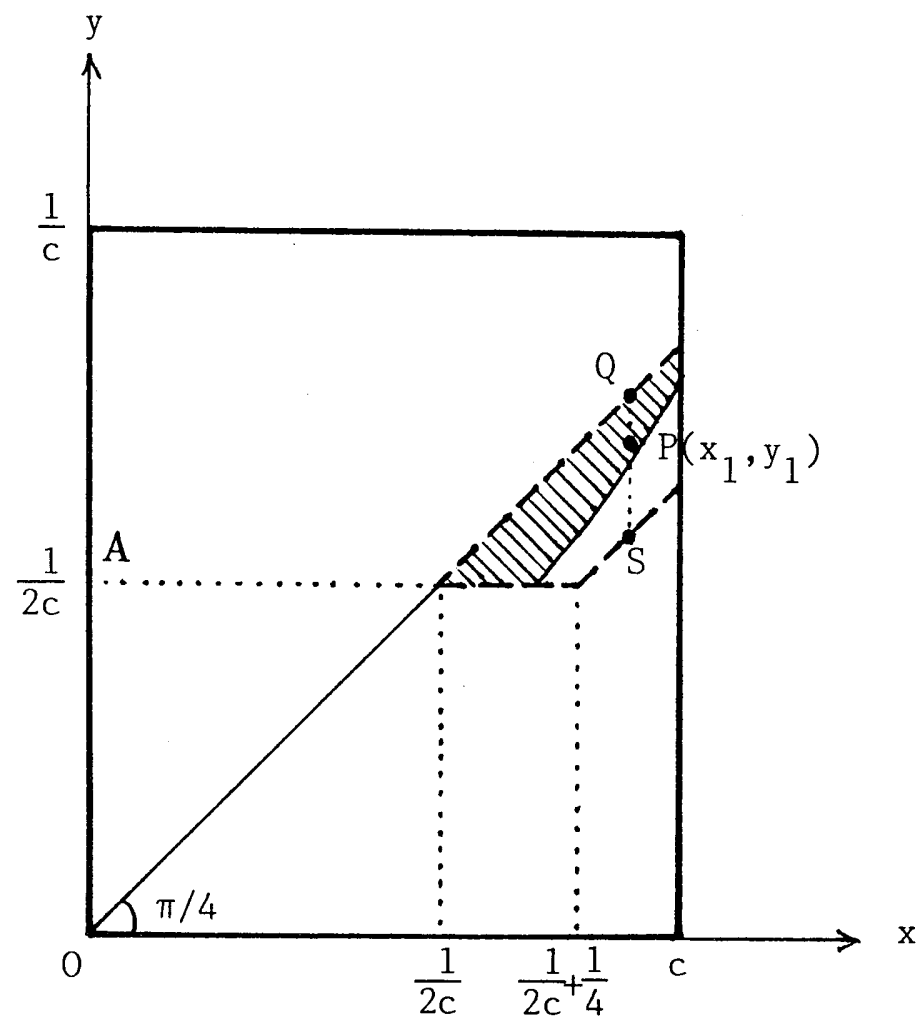

(2) $c<1$

Figure 3 Possible location of firm 1 (the leader) if firm 2 (the follower) were to locate at the corner $\mathrm{O}$ 